\title{
Methylmercury intoxication and histochemical demonstration of NADPH-diaphorase activity in the striate cortex of adult cats
}

R.B. Oliveira ${ }^{1}$ W. Gomes-Leal ${ }^{2}$ J.L.M. do-Nascimento 3 and C.W. Picanço-Diniz²

\author{
${ }^{1}$ Laboratório de Biologia Ambiental, Universidade Federal do Pará, \\ Santarém, PA, Brasil \\ Laboratórios de ${ }^{2}$ Biofísica Celular and ${ }^{3} \mathrm{~N}$ euroquímica Celular e Molecular, \\ Departamento de Fisiologia, Centro de Ciências Biológicas, \\ U niversidade Federal do Pará, Belém, PA, Brasil
}

\section{Correspondence \\ C.W. Picanço-Diniz \\ Passagem São Pedro, 99 \\ Rodovia do Coqueiro \\ 67113-000 Ananindeua, PA \\ Brasil \\ E-mail: leal@ marajo.ufpa.br}

Presented at the XIII Annual Meeting of the Federação de Sociedades de Biologia Experimental, Caxambu, MG, Brasil, August 26-29, 1998.

Research supported by FNMA, FINEP, CN Pq, CAPES, PRO PESP/ UFPa. W. Gomes-Leal was the recipient of a PIBIC-CN Pq fellowship.

Received April 13, 1998 Accepted June 29, 1998

\section{Abstract}

The effects of methylmercury ( $\mathrm{MeHg}$ ) on histochemical demonstration of the NADPH-diaphorase (NADPH-d) activity in the striate cortex were studied in 4 adult cats. Two animals were used as control. The contaminated animals received $50 \mathrm{ml}$ milk containing $0.42 \mu \mathrm{g}$ $\mathrm{MeHg}$ and $100 \mathrm{~g}$ fish containing $0.03 \mu \mathrm{g} \mathrm{MeHg}$ daily for 2 months. The level of MeHg in area 17 of intoxicated animals was $3.2 \mu \mathrm{g} / \mathrm{g}$ wet weight brain tissue. Two cats were perfused $24 \mathrm{~h}$ after the last dose (group 1) and the other animals were perfused 6 months later (group 2). After microtomy, sections were processed for NADPHd histochemistry procedures using the malic enzyme method. Dendritic branch counts were performed from camera lucida drawings for control and intoxicated animals $(\mathrm{N}=80)$. Average, standard deviation and Student $t$-test were calculated for each data group. The concentrations of mercury $(\mathrm{Hg})$ in milk, fish and brain tissue were measured by acid digestion of samples, followed by reduction of total $\mathrm{Hg}$ in the digested sample to metallic $\mathrm{Hg}$ using stannous chloride followed by atomic fluorescence analysis. Only group 2 revealed a reduction of the neuropil enzyme activity and morphometric analysis showed a reduction in dendritic field area and in the number of distal dendrite branches of the NADPHd neurons in the white matter $(\mathrm{P}<0.05)$. These results suggest that NADPHd neurons in the white matter are more vulnerable to the long-term effects of $\mathrm{MeHg}$ than NADPHd neurons in the gray matter.

Mercury $(\mathrm{Hg})$ in both organic and inorganic forms is a potent neurotoxic chemical. Methylmercury (MeHg), the organic form, is a poison which can affect different organs and systems. However, in all species the main target is the nervous system. In the central nervous system (CNS), the visual cortex and granular layer of the cerebellum are the major targets for the effects of $\mathrm{MeHg}$.

\section{Key words}

- NADPH-dehydrogenase

- Visual cortex

- Neurotoxicity

- Neuropil

- Mercury
These effects depend on factors such as the dose and time of exposure. Adult individuals contaminated with $\mathrm{MeHg}$ present neuronal lesions and the earliest clinical symptoms include dysarthria, ataxia and tunnel vision (1). The specific mechanism by which $\mathrm{MeHg}$ damages neurons is not fully understood. It was recently proposed that $\mathrm{MeHg}$ may impair astrocyte function with subsequent neu- 
ronal lesion (2-4). Indeed, a number of papers suggest that glial cells have an important role in neurotoxicity (4). Nevertheless, $\mathrm{MeHg}$ inhibits several mitochondrial enzymes, interferes with protein synthesis and alters the activity and transport of enzymes such as glutathione peroxidase, adenyl cyclase and dehydrogenases $(1,5,6)$. Inhibition of protein synthesis is observed after in vivo or in vitro exposure to $\mathrm{MeHg}$ and may be an early effect of $\mathrm{MeHg}$ (5). Thus, $\mathrm{MeHg}$ may alter the synthesis and activity of key enzymes in cell metabolism. These effects may extend to neurons that contain NADPH-diaphorase (NADPH-d), an NADPH-dependent enzyme that has been identified to be resistant to several neuropathological conditions such as NMDA neurotoxicity, stroke and some neurodegenerative disorders, such as Huntington, Parkinson and Alzheimer diseases $(7,8)$.

Mapping of NADPH-d throughout the nervous system became possible due to the pioneering work of Thomas and Pearse (7) who described "active solitary neurons" in non-fixed matter in the cerebral cortex and basal ganglia of various species. These cells were shown to be resistant to metabolic poisoning by substances such as carbon monoxide, sulfanylamide, thalidomide and tetrachloromethane vapor. Studies on these neurons were intensified after the discovery by Scherer-Singler et al. (9) that the enzyme activity was preserved in matter fixed with aldehydes. The work of Hope et al. (10) demonstrated that neuronal NADPH-d is a nitric oxide synthase (NOS), the enzyme that synthesizes nitric oxide (NO), a novel and unusual gaseous messenger molecule in mammalian tissues (11). Throughout the brain and peripheral paraformaldehyde-fixed tissues, all NOS-staining neurons also stain for NADPH-d (12). Paraformaldehyde fixation presumably inactivates virtually all NADPH-dependent oxidative enzymes except NOS, supporting the idea that the NADPH-d stain labels NOS neurons selec- tively (11). Therefore, NADPH-d histochemistry provides a simple method for the localization of this novel messenger system in the CNS. NO has been implicated in several physiological as well as pathological roles in the CNS which have been recently reviewed (13).

Despite the growing literature on the participation of NADPH-d/NOS in pathological conditions, at this time no studies have investigated the effects of $\mathrm{MeHg}$ on NADPHd-positive neurons (NADPHdn) of the striate cortex. Our study describes the histochemical activity pattern of this cell subgroup in the striate cortex of adult cats intoxicated with methylmercury chloride $(\mathrm{MeHgCl})$. Four cats were fed contaminated fish and milk daily for 2 months. Two animals were used as control. The contaminated animals received $50 \mathrm{ml}$ milk containing $0.42 \mu \mathrm{g} \mathrm{MeHg}$ and $100 \mathrm{~g}$ fish containing $0.03 \mu \mathrm{g} \mathrm{MeHg}$. Two intoxicated and 1 control cats were perfused $24 \mathrm{~h}$ after the last dose (group 1). The other 3 cats were perfused 6 months later (group 2) to compare the short- and long-term effects of MeHg. Perfusion was performed transcardially under deep anesthesia with intramuscular injection of ketamine $(11 \mathrm{mg} / \mathrm{kg}$ body weight) and xylazine $(0.55 \mathrm{mg} / \mathrm{kg}$ body weight $)$ with $0.9 \% \mathrm{NaCl}, 4 \%$ paraformaldehyde in $0.1 \mathrm{M}$ sodium phosphate buffer, $\mathrm{pH}$ 7.2-7.4, followed by sucrose/glycerol cryoprotective solutions (10, 20 and 40\%). After perfusion, sections of $200 \mu \mathrm{m}$ were prepared with a freezing microtome. All sections from the different animals were processed under the same incubation conditions for diaphorase histochemistry procedures using the malic enzyme method (9). Qualitative and quantitative analyses were done using photomicrographs and camera lucida drawings. A microcomputer program (Autocad) was used to measure soma and dendritic field area. Dendritic branch counts were performed from camera lucida drawings for control and intoxicated animals $(\mathrm{N}=80)$. Average, stan- 
dard deviation and Student $t$-test were calculated for each data group. The concentrations of mercury in milk, fish and brain tissue were measured by acid digestion of samples, followed by reduction of total $\mathrm{Hg}$ in the digested sample to metallic $\mathrm{Hg}$ using stannous chloride followed by atomic fluorescence analysis.

The morphologic pattern of NADPHdn in the control animals was similar to that already described elsewhere (14). The final concentration of $\mathrm{MeHg}$ in the visual cortex was $3.2 \mu \mathrm{g} / \mathrm{g}$ wet weight brain tissue. No differences in NADPHdn in gray matter were found between groups 1 and 2 for all parameters analyzed $(\mathrm{P}>0.05)$. Analysis of NADPHdn in the white matter showed a reduction of the number of distal branches (Figure 1) in group $2(\mathrm{P}<0.05)$ and of the dendritic area field (Figure 2). However, morphological alterations in NADPHdn in the white and gray matter were virtually impossible to distinguish by qualitative light microscopy analysis. The enzyme activity in the neuropil was considerably less intense in the brains of intoxicated animals belonging to group 2 when compared to control (not illustrated). No alterations were observed in group 1.

Different results for NADPHdn were observed in adult cat striate cortex after a short and long time of severe intoxication. The long-term effects of MeHg seem to affect mainly NADPH-diaphorase neurons in the white matter and the neuropil activity in the gray matter. Neurons in the gray matter did not seem to be altered by the schedule of treatment with $\mathrm{MeHg}$. Our results for the gray matter are similar to those reported by other authors who suggest a resistance of NADPH-positive neurons in gray matter to pathologic conditions like neurotoxicity mediated by NMDA receptors underlying stroke and neurodegenerative disorders, such as Huntington, Parkinson and Alzheimer diseases (7-8). It is unknown why these cells are resistant. This phenomenon may be a char-
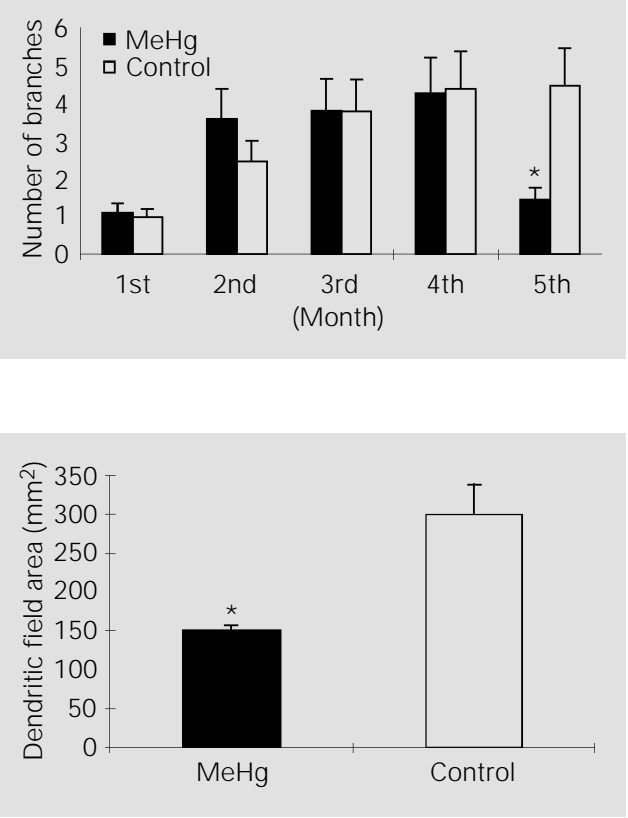

acteristic of gabaergic neurons, which have been shown to be resistant to toxic levels of NMDA in mouse cell culture (15). Cortical NADPHdn seem to synthesize GABA in the cerebral cortex (16). These inhibitory cells may present some protective "intrinsic safety factor" due to their important role in regulating cerebral excitability (15). Teleologically, this may denote that critical neuronal systems may be less vulnerable to pathological conditions in the CNS. Inhibitory cells constitute a critical neuronal system in cerebral cortex in that, despite their small number (only 20 to $25 \%$ of the total neurons in the cerebral cortex), they control the excitability of the entire brain. The resistance of NADPHdn to pathological insults is likely to be due to a number of functional adaptations including - perhaps the major characteristic an unusual metabolism.

The fact that the effects of MeHg were observed only after a long survival time of 6 months (group 2) may indicate that a long silent period is necessary for the effects of $\mathrm{MeHg}$ to appear. Indeed, it has been reported that some patients with Minamata disease developed the clinical features of severe poisoning after they had stopped eating the
Figure 1 - Number of dendritic branches of white matter NADPHd-positive neurons in the striate cortex of the adult cat 6 months after intoxication. Note that the number of more distal dendritic branches is significantly decreased in the treated animal compared to the control one $(* \mathrm{P}<0.05)$.

Figure 2 - Dendritic field area of white matter NADPHd-positive neurons in the striate cortex of the adult cat, 6 months after intoxication. Note the significant reduction of the values in the treated animal compared to the control one $(* \mathrm{P}<0.05)$. 
polluted fish (1). The silent period may represent the time necessary for $\mathrm{MeHg}$ to overcome the compensatory function of the CNS.

The decreased number of more distal branches in the white matter NADPH-diaphorase neurons matched the decreased dendritic field area. However, extensive quantification was necessary to show these results, indicating that NADPH-diaphorase neurons are affected only by high $\mathrm{MeHg}$ doses. Other authors have demonstrated a similar fact for NMDA excitoxicity in culture (15). Differences in neuronal vulnerability to pathological insults between white and gray matter may be related to glial function. A number of recent papers have suggested that astrocytes may play a major role in $\mathrm{MeHg}$ neurotoxicity (2-4). Astrocytes show basal levels of metallothioneins (MTs), metal-binding proteins whose biosynthesis is greatly enhanced by various factors including heavy metals such as $\mathrm{Zn}, \mathrm{Co}, \mathrm{Cd}$ and $\mathrm{Hg}$ (2). By virtue of their high thiol group (-SH) content, MTs have a very high affinity for $\mathrm{MeHg}$. Indeed, wherever an $\mathrm{MeHg}$ compound was identified in biological fluids, it was complexed with SH-containing ligands (2-3). The MeHgMT complex may keep $\mathrm{MeHg}$ in a relatively nontoxic form in astrocytes, thereby protecting both astrocytes and juxtaposed neurons from the cytotoxic effects of the metal (3). Thus, MT induction may cause CNS tolerance to $\mathrm{MeHg}$, at least during the early stages of intoxication. A recent report showed that in the human brain MT immunoreactivity was limited to a subpopulation that probably represented protoplasmic astrocytes (17). This astrocyte type is more characteristic in the gray matter, a possible reason for its lower vulnerability.

We found a striking decrease in diaphorase neuropil reactivity in group 2 , six months after MeHg intake. The anatomical substrate for diaphorase neuropil reactivity has not been fully determined. There is evidence from electron microscopy studies that the NADPHd reactivity in lamina $4 \mathrm{C}$ of pri- mates is mainly due to presynaptic axon terminals both from intra- and extracortical projections (18). The alterations of the intensity in NADPH-d activity in neuropil could suggest changes in transport processes of NADPH-diaphorase/NOS enzymes to distal branch regions of dendrites and axon terminals. This possibility agrees with the evidence that $\mathrm{MeHg}$ acts by altering both protein synthesis and transport $(1,5,6)$. The specific mechanism for these effects is unknown. Alterations in the integrity of microtubules has been reported in a variety of experimental systems (1). The decreased NADPHd neuropil reactivity may also be related to some type of astrocyte dysfunction. The astrocyte-mediated tolerance to $\mathrm{MeHg}$ (discussed above) may be an important factor to be overcome during the silent period of $\mathrm{MeHg}$ intoxication. Direct lesion of NADPHd axonal terminals may then occur. This possibility is under investigation by our group. Axonal terminals stained by iontophoretic injection of biocytin into the striate of the cats belonging to group 1 did not display qualitatively perceptible morphological alterations. However, we cannot rule out some subtle alterations such as a reduced number of axonal boutons (Gomes-Leal W, JesusSilva SG, Oliveira RB and Picanço-Diniz $\mathrm{CW}$, unpublished results).

Further studies are necessary to elucidate how $\mathrm{MeHg}$ damages the CNS as well as the specific dehydrogenase responses to $\mathrm{MeHg}$ neurotoxicity. However, for a proper estimate of the chronic effects of $\mathrm{MeHg}$, lower doses of the compound should be administered for prolonged periods of time. This approach would be closer to the actual situation occurring in the food chain around the contaminated environment. The fact that $\mathrm{MeHg}$ has great affinity for - $\mathrm{SH}$ groups may be both an important physiological and pathological finding in the CNS. Vulnerable -SH groups in both glial cells and neuron receptors could be potential targets for the effects of high $\mathrm{MeHg}$ levels during chronic expo- 
sure. Astroglial glutamate transporters carry out most of the functional glutamate transport and are essential for maintaining low extracellular glutamate (19). Higher doses and longer periods of exposure to $\mathrm{MeHg}$ may impair astrocyte function in terms of excitatory transmitter uptake (5). Thus, $\mathrm{MeHg}$ may damage the CNS through excitotoxic mechanisms like those mediated by NMDA. Indeed, ligand and voltage-gated ion channels represent a plausible early target for the action of $\mathrm{MeHg}$ (20). Since a large battery of events are mediated by ion channels, it follows that their disruption by mercurials could lead to potentially deleterious consequences for the cell. Thus, studies on mercury and other metal effects on the ion channels of neurons (including the NADPHdn subpopulation) and astrocytes represent a more sensitive method than histochemistry to study the chronic neurotoxic effects of metals on the nervous system. Such studies are now required to reveal the mechanisms that ensure protection of NADPHdn in the gray matter described in the present study and to determine why NADPHdn in the white matter and neuropil seem to be more vulnerable.

\section{Acknowledgments}

The authors are indebted to Erinaldo J. da Silva and Silmara S. Morais for preparing part of the drawings utilized for morphometric analysis in the present paper.

\section{References}

1. WHO (1991). IPCS, Enviromental Health Criteria 118. World Health Organization, Geneva.

2. Aschner M (1996). Methylmercury in astrocytes - What possible significance? Neurotoxicology, 17: 93-106.

3. Aschner $M$, Cherian MG, Klaassen $C D$, Palmiter RD, Erickson JC \& Bush Al (1997). Metallothioneins in brain - The role in physiology and pathology. Toxicology and Applied Pharmacology, 142: 229242.

4. Aschner M \& Kimelberg HK (1996). The Role of Glia in Neurotoxicity. CRC Press, Times Mirror International Publishers Ltd., New York.

5. Clarkson TW (1997). The toxicology of mercury. Critical Reviews in Clinical Laboratory Sciences, 34: 369-403.

6. Mottet NK, Vahter ME, Charleston J S \& Friberg LT (1997). Metabolism of methylmercury in the brain and its toxicological significance. Metal Ions in Biological Systems, 34: 371-403.

7. Thomas E \& Pearse AGE (1964). The solitary active cells. Histochemical demonstration of damage-resistant nerve cells with a TPH-diaphorase reaction. Acta Neuropathologica, 3: 238-249.

8. Ferrante RJ, Kowall NW, Beal MF, Richardson J $r$ EP, Bird ED \& Martin J B (1985). Selective sparing of a class of striatal neurons in Huntington's disease. Sci- ence, 230: 561-563.

9. Scherer-Singler $U$, Vincent $S R$, Kimura $H$ $\&$ McGeer FG (1983). Demonstration of a unique population of neurons with NADPH-diaphorase histochemistry. J ournal of Neuroscience Methods, 9: 229-234.

10. Hope BT, Michael GJ, Knigge KM \& Vincent SR (1991). Neuronal NADPH-diaphorase is a nitric oxide synthase. Proceedings of the National Academy of Sciences, USA, 88: 2811-2814.

11. Dawson TM \& Snyder SH (1994). Gases as biological messengers: Nitric oxide and carbon monoxide in the brain. J ournal of Neuroscience, 14: 5147-5159.

12. Dawson TM, Bredt DS, Fotuhi M, Hwang P \& Snyder SH (1991). Nitric oxide synthase and neuronal NADPH-diaphorase are identical in brain and peripheral tissues. Proceedings of the National Academy of Sciences, USA, 88: 7797-7801.

13. Wolf $\mathrm{G}$ (1997). Nitric oxide and nitric oxide synthase: biology, pathology, localization. Histology and Histopathology, 12: 251-261.

14. Mizukaua $K$, McGeer $P L$, Vincent $S R \&$ McGeer EG (1989). Distribution of reduced nicotinamide adenine dinucleotide phosphate (NADPH) diaphorase-positive cells and fibers in the cat central nervous system. J ournal of Comparative Neurology, 279: 281-311.

15. Tecoma ES \& Choi W (1989). GABAergic neocortical neurons are resistant to NMDA receptor-mediated injury. Neurology, 39: 676-682.

16. Valtschanoff J G, Weinberg RJ, Kharazia VN \& Schmidt HHHW (1993). Neurons in rat cerebral cortex that synthesize nitric oxide: NADPH-diaphorase histochemistry, NOS immunocytochemistry, and colocalization with GABA. Neuroscience Letters, 157: 157-161.

17. Blauwgeers HG, Sillevis-Smitt PA, De J ong J A \& Troost D (1993). Distribution of metallothionein in the human central nervous system. Glia, 8: 62-70.

18. Aoki C, Fenstemaker S, Lubin M \& Go GG (1993). Nitric oxide synthase in the visual cortex of monocular monkeys as revealed by light and electron microscopic immunocytochemistry. Brain Research, 620: 97-113.

19. Rothstein JD, Dykes-Hoberg M, Pardo $C A$, Bristol LA, J in L, Kunci RW, Kanai $Y$, Hediger MA, Wang Y, Schielk J P \& Welty DF (1996). Knockout of glutamate transporters reveals a major role for astroglial transport in excitoxicity and clearance of glutamate. Neuron, 16: 675-686.

20. Sorois J E \& Atchison WD (1996). Effects of mercurials on ligand- and voltage-gated ion channels: a review. Neurotoxicology, 17: 63-84. 